\title{
Uso de maconha na adolescência e risco de esquizofrenia
}

O abuso de maconha entre adolescentes dos países desenvolvidos vem aumentando significativamente nas últimas decadas. Uma das possíveis explicações para esse fato é a percepção de que a maconha é uma "droga leve", sem muitas conseqüências para a saúde do indivíduo, em contraste com outras drogas ilícitas. $\mathrm{Na}$ população brasileira, recente pesquisa da SENAD (Secretaria Nacional Antidrogas) demonstrou que 9\% dos adolescentes já utilizaram maconha pelo menos uma vez. ${ }^{1}$ Esse conceito, no entanto, tem sido contestado por recentes estudos longitudinais realizados na Europa e na Nova Zelândia ${ }^{2-5}$, que demonstraram uma associação positiva, numa curva de dose-efeito, entre o uso de maconha durante a adolescência e um risco aumentado do diagnóstico de esquizofrenia no futuro. Isso nos alerta para o fato de que o uso "inocente" de drogas durante a adolescência pode estar associado a importantes efeitos adversos a longo prazo.

É um fato bem estabelecido que pacientes esquizofrênicos tendem a fazer uso abusivo de drogas, o que tem sido relacionado a uma necessidade de auto-medicação para sintomas tão pertubadores. O que se observa em relação à maconha, contudo, é que muitas vezes o início do uso precede o aparecimento de sintomas esquizofrênicos. Isso levou alguns investigadores a hipotetizar que possivelmente o abuso de maconha funcionaria como um fator de risco para o desenvolvimento de sintomas esquizofrênicos em indivíduos vulneráveis. ${ }^{2-5}$

O primeiro desses estudos, descrevendo uma associação temporal entre o uso de maconha e a manifestação de sintomas esquizofrênicos, foi realizado na Suíça com 50 mil jovens. ${ }^{2,3}$ Depois de um seguimento de 15 anos, o uso de maconha durante a adolescência foi associado a um risco aumentado de esquizofrenia numa curva de dose-efeito. ${ }^{2}$ Entretanto, problemas sobre a validade diagnóstica e o possível efeito aditivo de outras drogas colocaram em questionamento os resultados preliminares desse estudo. Levantou-se também, baseado nos resultados desse estudo, a possibilidade de que os pacientes esquizofrênicos faziam uso de maconha para se auto-medicar. Numa segunda análise, publicada recentemente sobre a base de dados suíça, após 26 anos de seguimento, todos esses problemas iniciais foram levados em conta. ${ }^{3}$ Os resultados confirmam os achados iniciais de que o uso de maconha está associado com diagnóstico de esquizofrenia no futuro. ${ }^{3}$ Mais ainda: esse segundo estudo demonstrou uma associação positiva, numa curva de dose-efeito, e que a associação com o aparecimento de sintomas esquizofrênicos era menos consistente com o uso de outras drogas ao invés de maconha. ${ }^{3}$

Esses achados foram replicados em outros dois estudos realizados na Holanda e na Nova Zelândia. O primeiro estudo, tam- bém longitudinal, foi realizado numa população de 4.045 adolescentes e demonstrou um aumento de quase três vezes no risco de sintomas psicóticos em adolescentes que relataram uso frequente de maconha. ${ }^{4}$ No segundo estudo, com desenho de coorte com mais de mil adolescentes seguidos desde o nascimento, os jovens que relataram uso de maconha apresentaram uma chance quatro vezes maior de serem diagnosticados como portadores de transtorno esquizofreniforme aos 26 anos de idade. ${ }^{5}$

Apesar de apenas esses quatro estudos longitudinais terem sido realizados até o presente, os achados são consistentes e corroboram o argumento de que o uso de maconha apresentaria interação com outros fatores de risco, culminando na manifestação dos sintomas de esquizofrenia em indivíduos vulneráveis; além disso, os resultados desencorajam a hipótese de que a associação entre maconha e transtornos esquizofrênicos se deveria somente à auto-medicação. No entanto, não está claro, baseado nos achados atuais, se o uso da maconha seria responsável por iniciar os sintomas esquizofrênicos ou se causaria sintomas esquizofrênicos em pessoas não-vulneráveis.

É importante salientar o fato que não há nenhuma evidência na literatura de que o uso ocasional de maconha poderia provocar efeitos danosos. Entretanto, os achados dos presentes estudos são bastante relevantes, tanto sobre o ponto de vista clínico como sobre o ponto de vista de saúde pública. Como descrito anteriormente, o uso regular de maconha apresenta um risco potencial para o desenvolvimento de transtornos esquizofrênicos, particularmente em indivíduos vulneráveis. Mais ainda, esse risco parece estar diretamente relacionado à freqüência do uso de maconha, ou seja, jovens que iniciam o uso precocemente poderiam estar ainda mais vulneráveis aos efeitos danosos da droga. Iniciativas com o objetivo de reduzir o uso de maconha entre os jovens poderiam, portanto, ter um impacto positivo na prevenção de futuros casos de esquizofrenia. Campanhas que possam esclarecer esses achados para jovens, particularmente quando desenvolvidas de uma maneira criativa e envolvendo outros jovens, são necessárias e relevantes.

Karla Soares-Weiser
Department of Social Work, Bar Ilan University. Ramat
Gan, Israel
Mark Weiser
Michael Davidson
Sheba Medical Center. Tel Hashomer, Israel
Sackler School of Medicine, Tel Aviv University, Ramat
Aviv, Israel

Karla Soares-Weiser Gan, Israel

Mark Weiser

Sheba Medical Center. Tel Hashomer, Israel Aviv, Israel 


\section{Referências}

1. Carlini EA, Galduroz JCF, Noto AR, Nappo SA. Levantamento domiciliar sobre o uso de drogas psicotropicas no Brasil: estudo envolvendo 107 maiores cidades do país, 2001. São Paulo: Secretaria Nacional Antidrogas; 2002.

2. Andreasson S, Allebeck P, Engstrom A, Rydberg U. Cannabis and schizophrenia. A longitudinal study of Swedish conscripts. Lancet 1987;2(8574):1483-6.
3. Zammit S, Allebeck P, Andreasson S, Lundberg I, Lewis G. Self reported cannabis use as a risk factor for schizophrenia in Swedish conscripts of 1969: historical cohort study. BMJ 2002;325:1195.

4. van Os J, Bak M, Hanssen M, Bijl RV, de Graaf R, Verdoux H. Cannabis use and psychosis: a longitudinal population-based study. Am J Epidemiol 2002;156(4):319-27.

5. Arseneault L, Cannon M, Poulton R, Murray R, Caspi A, Moffitt TE Cannabis use in adolescence and risk for adult psychosis: longitudinal prospective study. BMJ 2002;325:1212-3. 